\title{
Diaphragmatic hernia in an adult cadaver: a case report
}

\author{
PUNJA, R. ${ }^{1 *}$, TEWARI, S. $^{2}$, MALSAWMZUALI, JC. ${ }^{1}$, \\ D'SOUZA, A. S. ${ }^{1}$ and KALTHUR, S. G. ${ }^{1}$ \\ ${ }^{1}$ Department of Anatomy, Kasturba Medical College, Manipal University, Madhavnagar, Manipal, Karnataka, India - 6104 \\ ${ }^{2}$ Kasturba Medical College, Manipal University, Madhavnagar, Manipal, Karnataka, India - 576104 \\ *E-mail: rohini.punja@manipal.edu
}

\begin{abstract}
Introduction: The diaphragm is a musculofibrous structure that separates the thoracic cavity from the abdominal cavity. Although it is a continuous sheet, developmentally it is derived from four different sources: the septum transversum, pleuroperitoneal membranes, lateral and dorsal body wall and the mesentery of oesophagus. Methodology: During routine dissection for undergraduate students in the department of Anatomy, Kasturba Medical College, Manipal a rare variation was encountered in a 65 year old female cadaver. Results: We observed a large defect in the left anterolateral aspect of the diaphragm with associated left pulmonary hypoplasia. The muscular contribution to the diaphragm from the left lateral and dorsal body wall was absent leading to the herniation of abdominal contents into the left thoracic cavity which included the stomach, intestinal loops, left colic flexure and the spleen. Conclusion: Diaphragmatic hernias presenting in adult life are rare and most commonly associated with a history of trauma. Congenital diaphragmatic hernia may remain asymptomatic as in the present case which is extremely rare and could be a chance finding during a routine chest x-ray. Knowledge of this anatomic defect in the diaphragm presenting in adult life would help prevent further complications leading to gastrointestinal or pulmonary distress.
\end{abstract}

Keywords: diaphragmatic hernia, pulmonary hypoplasia, abdominal viscera, congenital.

\section{Introduction}

Congenital Diaphragmatic Hernia $(\mathrm{CDH})$ seen in 1 in 2500 to 4000 live births and accounts for about $8 \%$ of all major congenital anomalies (BUDI, SHAILAJA, GANGA et al., 2013). Globally every 10 minutes a baby is born with $\mathrm{CDH}$. Posterolateral hernia that occurs through the foramen of Bochdalek is the most common type of congenital diaphragmatic hernia. Anterolateral congenital diaphragmatic hernia is an extremely rare entity. It is usually associated with lung hypoplasia and is commonly misdiagnosed as Morgagni's Hernia or Bochdalek hernia. We present a case of left anterolateral diaphragmatic hernia in a 65 year old female cadaver.

\section{Case Report}

During routine dissection classes for undergraduate medical students we encountered a rare variation in a 65 year old female cadaver. As we reflected the anterior thoracic wall herniated abdominal contents were seen occupying the left thoracic cavity and included the stomach, intestinal loops, left colic flexure and the spleen (Figure 1). We observed a large defect, measuring $6 \mathrm{~cm}$ antero-posteriorly and $6.8 \mathrm{~cm}$ transversely, in the left antero-lateral aspect of the diaphragm (Figures 2 and 3). The rest of the diaphragm and its openings showed no abnormalities. The abdominal and pelvic viscera as well as the perineum were normal. There was no mediastinal shift, however there was left pulmonary hypoplasia (Figure 4) and the presence of a single left pulmonary vein when the heart was inspected (Figure 5). There were no visible scar marks present in the trunk thus excluding any previous surgery or trauma.

\section{Discussion}

The most common etiology of diaphragmatic hernia in adults is trauma. Congenital diaphragmatic hernias $(\mathrm{CDH})$ presenting in adult life are extremely rare; with less than 100 published cases in literature.

\subsection{Congenital associations}

Many anomalies have been associated with $\mathrm{CDH}$. CDH may occur as an isolated defect or along with other entities as part of a syndrome (like thoraco-abdominal syndrome). Only $2 \%$ of it is estimated to be familial which could be autosomal dominant, autosomal recessive or $\mathrm{X}$ - linked. In neonates with abdominal wall defects and chromosomal abnormalities, we need to pay attention to the possible coexistence of $\mathrm{CDH}$ (INOUE, ODAKA, MUTA et al., 2016). CDH is not due to single gene mutation (BUDI, SHAILAJA, GANGA et al., 2013). Associated karyotype abnormalities are reported in $4 \%$ of CDH cases. Chromosomal anomalies like trisomy 13, trisomy 18, Pallister-Killian Mosaic Syndrome, and deletions of $1 \mathrm{q}, 8 \mathrm{p}$ and $15 \mathrm{q}$ have been reported in association with $\mathrm{CDH}$ (BUDI, SHAILAJA, GANGA et al., 2013; BIELINSKA, JAY, ERLICH et al., 2007). Transcriptional regulators have been hypothesized to contribute to the development of $\mathrm{CDH}$ (SAIFUDDIN and ARTHUR, 1993). Instance of CDH is more common in syndromic infants, particularly with Down syndrome, Cornelia, Fryns syndrome, Edwards syndrome and pentalogy of Cantrell (BUDI, SHAILAJA, GANGA et al., 2013; BIELINSKA, JAY, ERLICH et al., 2007). Complications associated with $\mathrm{CDH}$ include pulmonary hypoplasia, gastric volvulus, rotational abnormalities, midgut volvulus and bilateral renal hypertrophy (BUDI, SHAILAJA, GANGA et al., 2013; GUCCIARDO, DEPREST, DONE' et al., 2008). There may 


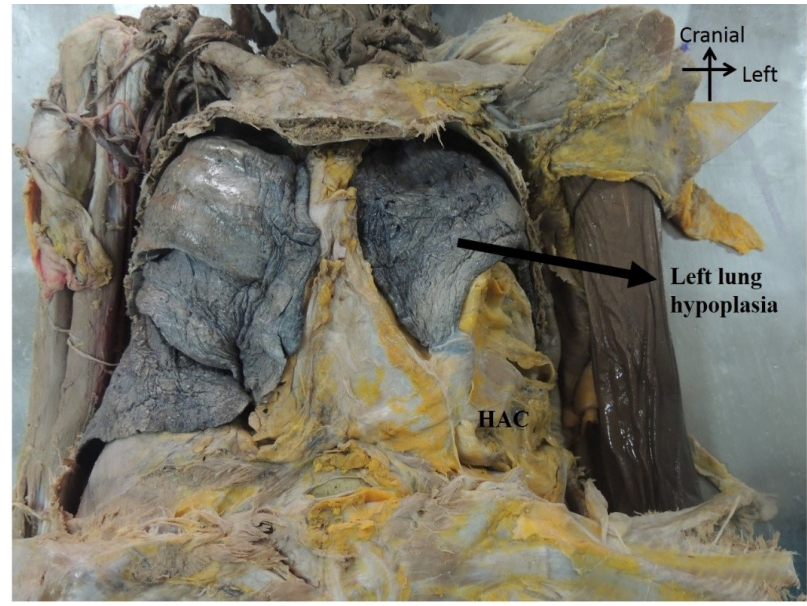

Figure 1. Herniated abdominal contents[HAC] seen occupying the left thoracic cavity. Anterior thoracic wall has been reflected.

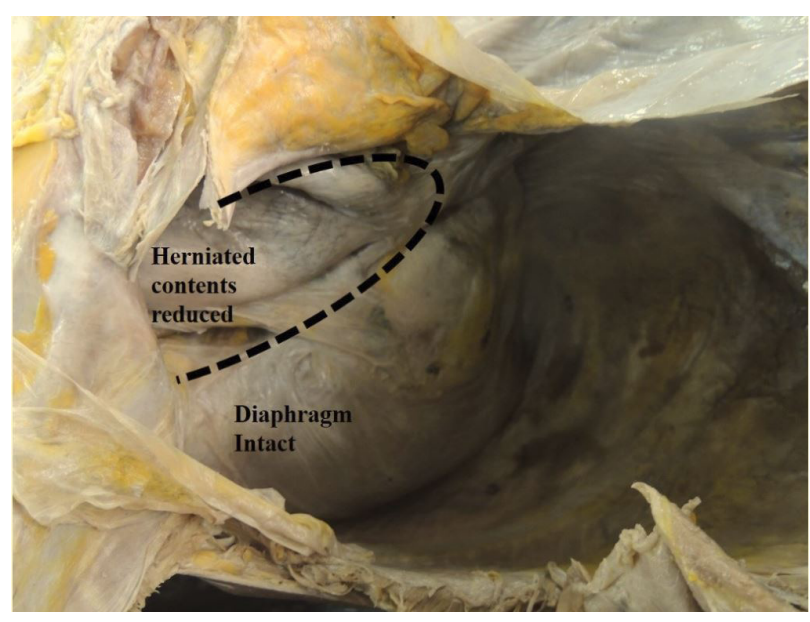

Figure 2. Margins of the defect in the diaphragm is highlighted with the dotted line. The muscular contribution in the left antero-lateral aspect of the diaphragm is absent whereas posteriorly it is intact. [View of left side of diaphragm after herniated contents reduced].

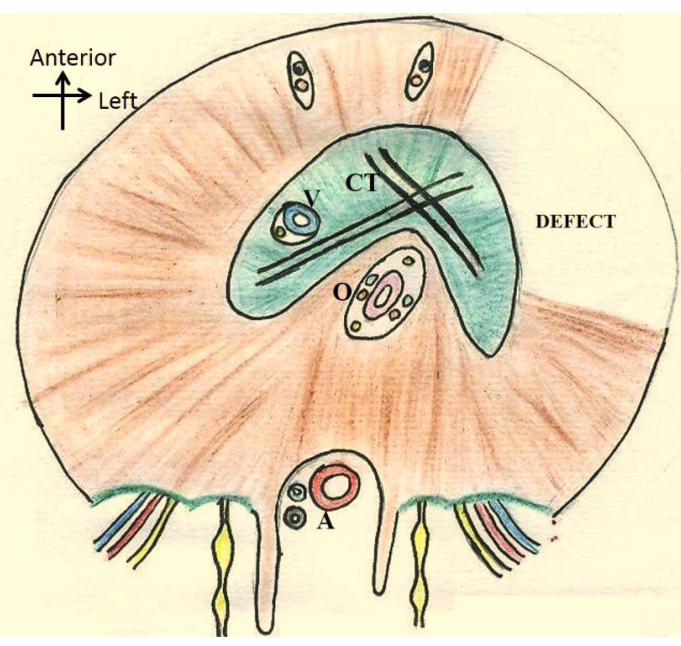

Figure 3. Hand drawn illustration of the diaphragm depicting the area of defect. (View of the diaphragm from below) CT - Central Tendon of diaphragm; V - Vena Caval opening; Oesophageal opening; A - Aortic opening.

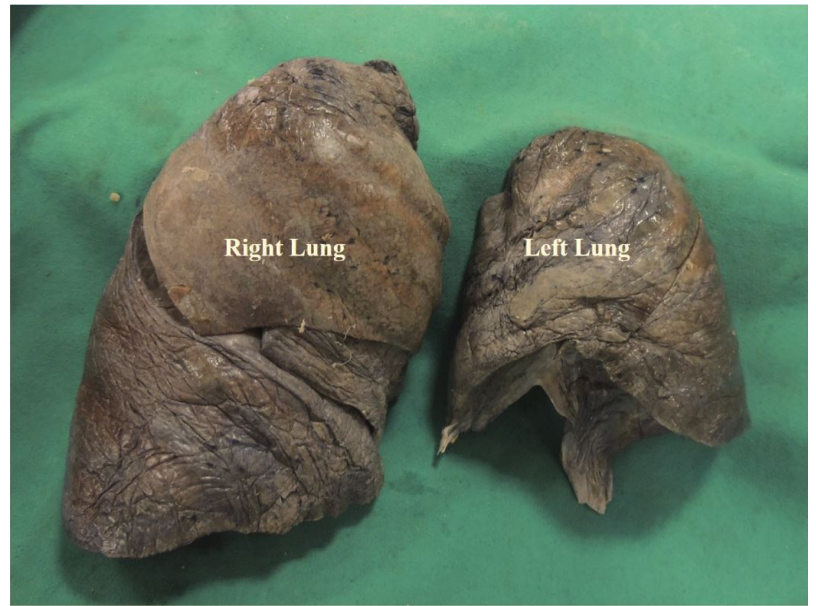

Figure 4. Left lung hypoplasia caused due to the herniated abdominal contents in the left thoracic cavity.

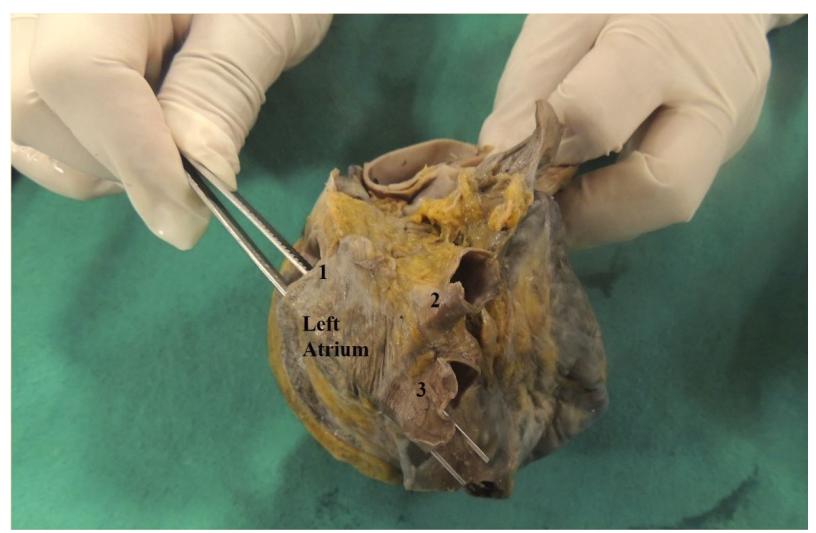

Figure 5. Specimen of the heart with a single left pulmonary vein. [Forceps entering the left pulmonary vein] 1- left pulmonary vein; 2,3 - right pulmonary veins.

be hypoplasia of the left ventricle with a left-sided hernia or pleural effusions caused by right-sided involvement. Prenatal ultrasound helps in early detection. Liver herniation might be associated with poor prognosis, and it can be used as a poor marker for prediction of outcome of fetal CDH (SARKAR and HAJRA, 2012).

\subsection{Embryological basis}

The diaphragm develops between $3^{\text {rd }}$ to $8^{\text {th }}$ weeks of intrauterine life. It develops from septum transversum, two pleuroperitoneal membranes, mesentery of esophagus \& three muscles of the body wall (cervical somite's) (HARTNETT, 2008).

1. Septum transversum develops from mesoderm caudal to the pericardial sac. Its caudal part contributes to liver whereas cranial part helps to form the diaphragm. Antero-median part of the diaphragm including central tendon, venacaval and esophageal openings develop from septum transversum (SONI, SINGH, SINGH et al., 2005).

2. Dorsal to the septum transversum, on either side of the dorsal mesentery of the esophagus, pleural and peritoneal cavities communicate through pleuroperitoneal canals. The fusion of 
septum transversum with pleuroperitoneal membranes and structures around the esophageal mesentery begins the closure of pleuroperitoneal canals, with the right side closing before the left (SHEHATA and LIN, 2012). This may be the reason why most of the congenital diaphragmatic hernias tend to occur on the left side. Although pleuroperitoneal membranes form large portions of fetal diaphragm, they represent relatively small portions of the newborn infant's diaphragm (SONI, SINGH, SINGH et al., 2005; MOORE and PERSAUD, 2003).

3. Dorsal esophageal mesentery provides central point of fusion for septum transversum and the pleuroperitoneal membranes and gives rise to the median part of diaphragm present between esophageal and aortic openings (SONI, SINGH, SINGH et al., 2005).

4. Peripheral part of the diaphragm develops from shelf like projections of the body wall. During fifth week, myoblasts from the third, fourth and fifth cervical somite's migrate into developing diaphragm bring their nerve- the phrenic nerve with them (SKANDALAKIS, 2004; CLUGSTON and GREER, 2007).

Between 9-12 weeks of gestation, the pleural cavities expand into lateral body wall and finally penetrate into the wall. The musculature and innervations of diaphragm is completed by about $10^{\text {th }}$ week (CLUGSTON and GREER, 2007). There may be failure of development of any one of the aforesaid components or their fusion which will lead to $\mathrm{CDH}$. Parasternal hernia through Foramen of Morgagni and hernia through esophageal hiatus are occasionally seen (MOORE and PERSAUD, 2003).

Bilateral CDH is observed in $2 \%$ of cases and high incidence of bilateral $\mathrm{CDH}$ is associated with familial etiology. Multiple unilateral CDH can also occur. Akel and Nasr (2001) have reported six cases of $\mathrm{CDH}$ with multiple defects in the right side of central tendon of the diaphragm. The present case is a unilateral isolated defect with associated lung hypoplasia. The muscular contribution to the diaphragm from the left lateral and dorsal body wall was absent leading to the herniation of abdominal contents into the left thoracic cavity. The presence of lung hypoplasia confirms that this is a congenital defect. If a diaphragmatic hernia develops toward the end of pregnancy or after birth, pulmonary hypoplasia does not occur (GUCCIARDO, DEPREST, DONE' et al., 2008). We also stated that only 3 pulmonary veins were seen in our case. Saifuddin and Arthur (1993) reported that in $\mathrm{CDH}$ the pulmonary vasculature is also affected to a greater degree than the bronchial tree.

The diagnosis of congenital diaphragmatic hernias typically occurs prior to delivery but $5-25 \%$ of cases are late presenting, after the neonatal period (BUDI, SHAILAJA, GANGA et al., 2013). The most frequently encountered type of $\mathrm{CDH}$ is posterolateral hernia, through the foramen of Bochdalek.

Anterolateral congenital diaphragmatic hernias are extremely rare. The clinical presentation in adults and pediatric age group is different. Clinical manifestations vary from asymptomatic to severe respiratory distress. Scahill, Maak, Kunder et al. (2013) described a case of anterolateral congenital diaphragmatic hernia with omphalocoele in a female newborn patient who died due to respiratory failure despite intensive care support, due to secondary lung hypoplasia.

It is believed that the delay or absence of symptoms may be due to occlusion of the diaphragmatic defect by the intra- abdominal viscus (NITECKI and BAR-MAOR, 1992). Increase in intraabdominal pressure, which occurs in pregnancy, may also lead to late manifestation in some cases (ALAM and CHANDER, 2005). It is possible that due to the large defect in our case, the patient never experienced any symptoms of intestinal obstruction and strangulation, as the defect was large enough to allow free movement of herniated contents, into and out of the thoracic cavity. Since the clinical presentation is varied, a high degree of clinical suspicion coupled with imaging studies lead to an early and accurate diagnosis. Contrast enhanced CT is the most effective modality for detection of diaphragmatic hernia. It provides detailed information regarding the herniated viscera and the diaphragmatic defect (ALAM and CHANDER, 2005).

Prenatal ultrasonography helps in early detection of congenital hernias. Features indicative of congenital diaphragmatic hernia are polyhydramnios, presence of intrathoracic stomach bubble, mediastinal and cardiac shift away from the side of herniation and rarely fetal hydrops (BUDI, SHAILAJA, GANGA et al., 2013; ALAM and CHANDER, 2005). Some cases may be asymptomatic and are accidentally detected on routine examination, usually by X-ray. Mouroux, Pop, Guiraudet et al. (2008) reported a case of anterolateral diaphragmatic hernia in a 76 year old male who presented with a blocking respiratory symptom in left hemithorax, especially after meals and occasionally associated with vomiting. They believed that it was a "weakness hernia" due to weak muscle tone of the diaphragm, similar to bilateral inguinal hernia the patient had had years ago, as there was no history of trauma (MOUROUX, POP, GUIRAUDET et al., 2008). However, the presence of left lung hypoplasia in our case confirms that it was a congenital defect that went unnoticed throughout life.

Anterolateral congenital diaphragmatic hernia needs to be differentiated from Morgagni Hernia (STEINER and MARES, 1993). Foramen of Morgagni are small triangular areas on either side of inferior end of sternum on the anterior aspect of the diaphragm. The size and lateral extension of anterolateral diaphragmatic hernia helps to differentiate it from other anterior diaphragmatic hernias (STEINER and MARES, 1993). Also, anterolateral CDH is almost always associated with lung hypoplasia. Although the herniated contents are similar to those in Bochdalek hernia, but the defect is anterolateral not posterolateral in position.

\section{Conclusion}

Diaphragmatic hernias presenting in adult life are rare and most commonly associated with a history of trauma. Congenital diaphragmatic hernia may remain asymptomatic as in the present case, and could be a chance finding during a routine chest x-ray. Anterolateral congenital diaphragmatic hernia is an extremely rare and underemphasized entity (STEINER and MARES, 1993). It is commonly misdiagnosed as Morgagni hernia or as other anterior diaphragmatic hernias. Knowledge of this anatomic defect in the diaphragm presenting in adult life would help prevent further complications leading to gastrointestinal or pulmonary distress.

\section{Conflict of interest}

The authors declare that they have no conflict of interest. 


\section{References}

AKEL, S. and NASR, W. Multiple ipsilateral congenital diaphragmatic pathologies: rarities to consider. European Journal of Pediatric Surgery, 2001, vol. 11, n. 3, p. 200-203. PMid:11475119. http://dx.doi. org/10.1055/s-2001-15492.

ALAM, A. and CHANDER, B. Adult Bochdalek Hernia. Medical Journal, Armed Forces India, 2005, vol. 61, n. 3, p. 284-286. PMid:27407781. http://dx.doi.org/10.1016/S0377-1237(05)80177-7.

BIELINSKA, M., JAY, P.Y., ERLICH, J.M., MANNISTO, S., URBAN, Z., HEIKINHEIMO, M. and WILSON, DB. Molecular genetics of congenital diaphragmatic defects. Annals of Medicine, 2007, vol. 39, n. 4, p. 261-274. PMid:17558598. http://dx.doi. org/10.1080/07853890701326883.

BUDI, S., SHAILAJA, C., GANGA, G.M. and ANGADI, A.V. Foramen of morgagni hernia in an adult cadaver: embryological basis. Anatomica Karnataka., 2013, vol. 7, n. 3, p. 52-55.

CLUGSTON, R.D. and GREER, J.J. Diaphragm development and congenital diaphragmatic hernia. Seminars in Pediatric Surgery, 2007, vol. 16, n. 2, p. 94-100. PMid:17462561. http://dx.doi. org/10.1053/j.sempedsurg.2007.01.004.

GUCCIARDO, L., DEPREST, J., DONE', E., VAN MIEGHEM, T., VAN DE VELDE, M., GRATACOS, E., JANI, J., PERALTA, F. and NICOLAIDES, K. Prediction of outcome in isolated congenital diaphragmatic hernia and its consequences for fetal therapy. Best Practice o Research. Clinical Obstetrics of Gynaecology, 2008, vol. 22, n. 1, p. 123-138. PMid:18082455. http://dx.doi.org/10.1016/j. bpobgyn.2007.08.006.

HARTNETT, K.S. Congenital diaphragmatic hernia: advanced physiology and care concepts. Advances in Neonatal Care, 2008, vol. 8, n. 2, p. 107-115. PMid:18418208. http://dx.doi.org/10.1097/01. ANC.0000317259.60954.dl.

INOUE, S., ODAKA, A., MUTA, Y., BECK, Y., SOBAJIMA, H. and TAMURA, M. Coexistence of congenital diaphragmatic hernia and abdominal wall closure defect with chromosomal abnormality: two case reports. Journal of Medical Case Reports, 2016, vol. 10, n. 1, p. 19. PMid:26800685. http://dx.doi.org/10.1186/s13256-016-0805-y.

MOORE, KL. and PERSAUD, TVN. The developing human: clinically oriented embryoplogy. 7th ed. Philadelphia: W.B Saunders Company; 2003. p. $195-200$

MOUROUX, J., POP, D., GUIRAUDET, P., GIOVANETTI, R. LAURON, J. and VENISSAC, N. A new type of diaphragmatic hernia:
Anterolateral hernia. The Journal of Thoracic and Cardiovascular Surgery, 2008, vol. 135, n. 4, p. 955-956. PMid:18374792. http:// dx.doi.org/10.1016/j.jtcvs.2007.12.001.

NITECKI, S. and BAR-MAOR, JA. Late presentation of Bochdalek hernia: our experience and review of the literature. Israel Journal of Medical Sciences, 1992, vol. 28, n. 10, p. 711-714. PMid:1399500.

SAIFUDDIN, A. and ARTHUR, RJ. Congenital diaphragmatic hernia--a review of pre- and postoperative chest radiology. Clinical Radiology, 1993, vol. 47, n. 2, p. 104-110. PMid:8435953. http:// dx.doi.org/10.1016/S0009-9260(05)81182-1.

SARKAR, A. and HAJRA, DSG. Right sided congenital diaphragmatic hernia: a case report with a brief review. Journal of the Anatomical Society of India, 2012, vol. 61, n. 1, p. 53-56. http://dx.doi.org/10.1016/ S0003-2778(12)80014-1.

SCAHILL, M.D., MAAK, P., KUNDER, C. and HALAMEK, L.P. Anterolateral congenital diaphragmatic hernia with omphalocele: A case report and literature review. American Journal of Medical Genetics. Part A, 2013, vol. 161A, n. 3, p. 585-588. PMid:23401132. http:// dx.doi.org/10.1002/ajmg.a.35703.

SHEHATA, BM. and LIN, J. Congenital diaphragmatic hernia with emphasis on embryology, subtypes, and molecular genetics, congenital diaphragmatic hernia. In MOLLOY, E. (Ed.). Prenatal to childhood management and outcomes. InTech; 2012. Available from: <http:// www.intechopen.com/books/congenital-diaphragmatic-herniaprenatal-to-childhood-management-and-outcomes/congenitaldiaphragmatic-hernia-with-emphasis-on-embryology-subtypes-andmolecular-genetics>. Access in: 28 July 2016.

SKANDALAKIS, J. Diaphragm surgical anatomy: the embryologic and anatomical basis of modern surgery. Athens: Paschaladis Medical Publications; 2004. p. 353-392. vol. 1.

SONI, A., SINGH, P., SINGH, R. J. and SOOD, V. Eventration of Diaphragm: embryological basis. Journal of the Anatomical Society of India, 2005, vol. 54, n. 2, p. 39-41.

STEINER, Z and MARES, AJ. Anterolateral diaphragmatic hernia: is it a Morgagni hernia? European Journal of Pediatric Surgery, 1993, vol. 3, n. 2, p. 112-114. PMid:8323917. http://dx.doi. org/10.1055/s-2008-1063524. 